\title{
DOCÊNCIA NO ENSINO SUPERIOR: IDENTIDADE E PROFISSÃO DOCENTE NA LICENCIATURA
}

\author{
Edinaldo Alves da Purificação ${ }^{1}$
}

RESUMO: O trabalho referente aborda sobre a docência superior, em que a identidade profissional é uma percursora de análise sobre "o ser" professor e a profissão docente na licenciatura como aquisição de conhecimento. Os objetivos desse artigo são compreender a construção da identidade perante a docência, principalmente na licenciatura; analisar como a formação docente interfere na identidade do docente para a atuação na licenciatura; avaliar a profissão docente através de aspectos e contextos que enfatizam o seu estudo; relacionar a identidade com a formação docente na licenciatura na busca de conduzir o conhecimento dessa área. A metodologia para este artigo consistiu em uma pesquisa qualitativa de porte da pesquisa bibliográfica investigados os contextos em livros, artigos científicos e periódicos para uma comprovação dos fatos coletados de acordo com o tema proposto. A primeira parte aborda a formação da identidade do docente em que explica os aspectos para a sua construção, transformação e adequação, a segunda parte trata das reflexões sobre a profissão docente e a terceira parte que discuti sobre a perspectiva da identidade e profissão docente na licenciatura. Com isso, a identidade é uma construção reflexiva do docente que deve desenvolvê-la desde cedo e perceber aprimorá-la.

Palavras-chave: Identidade. Formação. docente e didática.

\footnotetext{
${ }^{I}$ Estudante de mestrado Minter em Ciências Educacionais, Universidade Francis Xavier, em São Paulo (2020), Cursista no ensino superior do curso de graduação de Gestão de Tecnologia da Informação na Faculdade Estácio, no Amazonas (2020), Bolsista da Fundação de Amparo à Pesquisa do Estado do Amazonas FAPEAM, em Manaus (2020), Professor da Secretaria de Educação e Desporto do Amazonas - SEC/AM (2016), atuou como Tutor de Educação a Distância no Instituto Federal de Educação, Ciências e Tecnologia Baiano - IFBAIANO - Polo Valença - BA ,(2015-2016), Professor pela Secretária de Educação e Desporto da Bahia, em Santo Estevão - BA, SEC/BA como REDA (2015-2016), Professor da FARB (Faculdade Regional da Bahia) de Feira de Santana - UNIRB (2015-2016), Professor da Faculdade Regional da Bahia - FARB, em Feira de Santana - BA (2014-2016), Professor da Instituição de Educação e Formação Livre - IEFL, em Ipirá (20142015), Professor do Colégio Piaget - Sociedade Educacional Valentense LTDA (2014), Professor da Faculdade Unidas de Feira de Santana - FUFS - BA (2013-2014), Editor e produtor de módulos para cursos de pósgraduação Stricto Sensu pelo Instituto Pró-Saber - FINOM, em Feira de Santana - BA (2012), Professor da Faculdade de Tecnologia e Ciências - FTC - em Feira de Santana - BA (20II), Graduado em Matemática pela Universidade Estadual de Feira de Santana - UEFS - BA (2009), Estagiário como professor no Colégio Estadual Luiz Viana Filho, em Feira de Santana - BA (2008-2009), Estágiário como professor do Ginásio Municipal Pós-Graduação Em Matemática Financeira e Estatística pelo Colégio Noroeste de Minas Gerais (20I1) - FINOM - MG e Técnico em Rotinas Administrativas pela Microlins (2012) - Feira de Santana Ba. Email: profedinaldoalves@gmail.com.
} 
ABSTRACT: The reference work addresses higher teaching, in which professional identity is a precursor of analysis on "the being" teacher and the teaching profession in the degree as knowledge acquisition. The objectives of this article are to understand the construction of identity in the face of teaching, especially in the degree; analyze how teacher education interferes in the identity of the teacher for the performance in the degree; evaluate the teaching profession through aspects and contexts that emphasize its study; relate the identity with the teacher training in the degree in the search to conduct knowledge in this area. The methodology for this article consisted of a qualitative research of bibliographic research investigated the contexts in books, scientific articles and journals for a proof of the facts collected according to the proposed theme. The first part addresses the formation of the identity of the teacher in which he explains the aspects for its construction, transformation and adequacy, the second part deals with reflections on the teaching profession and the third part that I discussed about the perspective of identity and teaching profession in the undergraduate degree. Twitch this, identity is a reflective construction of the teacher who must develop it. from an early age and perceive improving it.

Keywords: Identity. Training. teacher and didactics.

\section{INTRODUÇÃO}

A Docência Superior é um ramo na qual desenvolve um trabalho de constante modificações, por uma parte temporal e a outra espacial, cabendo a se adequar nas diversas situações do processo de ensino-aprendizagem e na formação de novos docentes. Na parte temporal o compromisso de acompanhar as mudanças que a sociedade desenvolve com o passar dos anos, devido ao seu contexto histórico, já por outro lado, a parte espacial por mudanças políticas educacionais que adquirem uma abrangência mais complexa sobre a educação em que luta por sua permanência primordial na sociedade. Pois:

\footnotetext{
A profissão de professor, como todas as profissões, emerge de naturezas diversas, em contextos específicos e em diferentes momentos históricos como respostas às necessidades exigidas pelas sociedades, adquirindo, assim, estatuto de legalidade. A profissão docente é uma prática social, portanto exige-se atualmente a sua transformação para que adquira novas características para as quais respondam às novas demandas da sociedade. (LIMA, 2009, p.68).
}

Visto que, à Docência Superior desenvolveu vários debates por especialistas, esse trabalho explana a identidade e formação docente na licenciatura como foco de análise no perfil da educação, de modo a analisar as características de ambas como critério de 
construção e formação de novos docentes. Diante desse fato, surgiu o questionamento: Como obter na Docência Superior uma identidade junto a formação docente na licenciatura? Por isso, uma análise sobre aspectos positivos e negativos da docência é fundamental ser estudada, pois, uma das ferramentas que possa evoluir a identidade e a formação do professor na licenciatura se adere a sua didática e metodologia do ensino. Pelo motivo, esses dois campi são responsáveis na construção reflexiva e atitudinal do próprio docente em analisar o seu contexto profissional e aprimorá-lo

A escolha do tema DOCÊNCIA NO ENSINO SUPERIOR: Identidade e profissão docente na licenciatura, atribui-se por constante conflitos que existem no campo educacional, pois muitos docentes já confirmaram que estão nessa área apenas por sobrevivência e acaba isso refletindo para os alunos em sala de aula e outros não sabem como lidar com a sala de aula gerando dúvidas até se é apto a seguir à docência. Como afirma Lima (2009, p.68): “O processo de desvelamento da constituição da identidade pressupõe um maior conhecimento de si, do outro, condições essenciais para o exercício profissional."

A identidade é um processo que é lentamente construído, necessita de tempo e adequação do conhecimento não apenas na área de formação que o docente adquiri, mas de uma amplitude que ultrapasse esse conhecimento. A necessidade de pesquisar se torna um ponto forte para produzir a transmissão de conhecimento mostrando a habilidade de ser docente onde faz parte também da formação docente. Como explica Ximenes (2006, p.46): "Repensarmos a formação docente e o exercício profissional da docência implica em revermos nossa concepção do ato de educar e como estamos a construir nossa identidade de profissional docente.” E, também Lima (2009, p.12): “(...) a construção identitária é um processo inacabado e contínuo, ou seja, indicam que a identidade pessoal e profissional transforma-se, acompanhando o movimento da realidade socialmente construída, (...)”. (Lima, 2009, p.12

Dessa forma a pesquisa tem por objetivos a compreender a construção da identidade perante a docência, principalmente na licenciatura; analisar como a formação docente interfere na identidade do docente para a atuação na licenciatura; avaliar a profissão docente através de aspectos e contextos que enfatizam o seu estudo; relacionar a identidade com a formação docente na licenciatura na busca de conduzir o conhecimento dessa área. 
Para essa pesquisa foram consultadas obras de Lima (2009), Ximenes (202I), Barbosa (2003), Libâneo (1998), Neu e Marchesan (2020), Diniz e Rodrigues (2020) e Burchard et al. (2020), no intuito de aprofundar o estudo do tema e obter melhor esclarecimento tanto da identidade como na formação docente na licenciatura para consolidar uma pesquisa qualitativa.

A metodologia da pesquisa desenvolvida teve uma escolha no princípio da pesquisa qualitativa:

Neste sentido, realçamos que as pesquisas qualitativas contribuem significativamente para a análise crítica da educação brasileira, principalmente sobre o cotidiano escolar propondo a articulação da formação com a prática pedagógica do professor através de ações reflexivas e colaborativas. (LIMA, 2009, p. 24).

E uma das pesquisas que se adere exatamente por ser qualitativa é a pesquisa bibliográfica, desde que: "Sua finalidade é proporcionar ao aluno ou ao pesquisador o acesso à literatura produzida sobre determinado assunto, servindo de apoio para o desenvolvimento de trabalhos científicos e análise das pesquisas.” (UEG, 2008). Indiscutivelmente, a pesquisa bibliográfica é um método para levantar e buscar respostas aos questionamentos de cunho científico para as diversas área da sociedade de forma explanar as possibilidades de soluções de um problema.

Dante disso o artigo foi dividido em três partes: A primeira parte aborda a formação da identidade do docente onde explica os aspectos para a sua construção, transformação e adequação, por isso a importância de conhecer sobre a identidade quando é um docente. A segunda parte trata das reflexões sobre a profissão docente em que é contada um percurso de aspectos positivos e negativos na profissão para lidar em sua atuação, em que existem os altos e os baixos que podemos encontrar ao atuar. E por fim, a terceira parte que discuti sobre a perspectiva da identidade e profissão docente na licenciatura para uma demonstração do que se espera as relações entre esses dois aspectos na construção da educação e o motivo da didática ser a percursora na licenciatura para evolução.

Esse artigo é uma produção para que o campo científico da educação possa ter um conhecimento a respeito da Docência Superior, visto que se trata de um conjunto de aspectos que determinam a formação do profissional. As relações estabelecidas servirão para que 
futuros pesquisadores possam contribuir para aprimoração de pesquisas a ser desenvolvida na área e socialmente contribui para uma reflexão sobre o pensar e o agir na licenciatura.

Assim enfatiza Diniz e Rodrigues (2020):

\begin{abstract}
Não obstante, essas reflexões em relação à identidade docente a partir de um contexto social multifacetado ressaltam que na atualidade o docente vivencia inquietações e perplexidades em seu cotidiano, o que reforça a necessidade de apostar nas suas potencialidades para gerir com bom desempenho os enfrentamentos cotidianos. (p.7).
\end{abstract}

A identidade não surgi por um acaso, depende muito da habilidade de adquirir conhecimento e olhar por volta de si mesmo para que o docente possa encontrar novos métodos no seu ensino. Por isso, a licenciatura é uma área aberta a transformação e progressão do conhecimento de "aprender a ensinar" e "ensinar a aprender". Mediante ao cenário atual a licenciatura preocupa-se com a atuação do professor em sala de aula para que possa debater seus conflitos e o seu sucesso no processo de ensino aprendizagem, pois a troca de experiência consolida, entre os demais profissionais dessa área, um enriquecimento educacional na sociedade.

\title{
A FORMAÇÃO DA IDENTIDADE DO DOCENTE
}

Ser docente refere-se primeiramente a transmitir o conhecimento de uma determinada área. Contudo, para efetuar tal prioridade existe um aspecto em que passa despercebido por alguns profissionais que é a identidade.

Uma definição na qual podemos perceber o quanto é importante conhecer sobre a identidade profissional, nas palavras de Lima (2009), papeia-se como:

\footnotetext{
A identidade profissional é um processo que se constrói historicamente pela significação social de uma determinada profissão e da revisão constante dos significados atribuídos a atividade profissional, ou seja, identidade se constitui a partir da inserção dos indivíduos em determinados espaços sociais, de vida e de trabalho. (p.14).
}

Nesse aspecto, a autora analisa a identidade como uma experiência em determinado campo educacional para que possa identificar o indivíduo através da inclusão no meio social e profissional, resumindo identidade é a inserção do indivíduo naquele meio que ele convive.

Formar uma identidade não significa apenas expor que por ser docente tem a habilidade de domínio de diversos assuntos, mas significa adquirir experiências para uma 
reflexão no ato de consolidar o processo de ensino aprendizagem, seja ela de vínculo atitudinal ou processual.

Posto que: "A identidade considerada como uma formação social e histórica é transformação, pois é um processo contínuo, extremamente complexo que sempre se constitui como metamorfose no percurso de vida.” (LIMA, 2009, p.65). Assim, pode ser entendido que a formação da identidade necessita do tempo do percurso profissional na docência, pois se refere a um conjunto de fatores que no indivíduo venha de fora para dentro, pois, é preciso atuar para refletir, na busca de soluções e adequações para ensinar.

De modo que Lima (2009) refere-se a identidade também como "um processo dialético", caracterizado por "mudanças e transformações” com a possibilidade de o docente construir e reconstruir, tanto a sua identidade pessoal como a sua identidade profissional. A identidade pessoal é a experiência vivenciada pelo individuo ligado a fatores sociocultural enquanto, onde se difere no conceito que a autora aborda recentemente sobre a identidade profissional que é restrita a um grupo.

Destaca-se identicamente que a formação da identidade do docente pode ultrapassar os conhecimentos formativos e adquiridos deste profissional: "Destarte, compreende-se que a formação da identidade docente é ampla e conecta-se de forma que o perfil elaborado desse profissional perpassa por caminhos para além do conhecimento, dentre eles, as habilidades, as competências e os saberes." (NEU E MARCHESAN, 2020, p.29). Compreende-se que o docente deve conhecer e perambular por diversas áreas para que possa ser multidisciplinar na transmissão do conhecimento.

A importância da formação da identidade do docente deu-se através de experiências e observações expostas em contato com demais docentes na procura de uma qualificação e evolução do processo de ensino-aprendizagem dos alunos, assim criaram-se diversos debates desde a postura "de ser docente" como "efetuar a docência". Aspectos estes refletidos por Lima (2009), que destaca:

[...] é de fundamental relevância quando tratamos da constituição da identidade profissional docente, como um dos elementos necessários ao exercício profissional competente, haja vista que oportuniza refletir sobre a formação inicial e continuada de professores, sobre a sua prática pedagógica, a relação com os pares e com os alunos e com a instituição em que exercem a sua atividade profissional, dando 
suporte para definirmos como nos vemos e sentimos como sendo professor e como nos identificamos com o ser professor. (p.46).

Do ponto de vista da autora a prática pedagógica é a ferramenta que conduz a formação da identidade do docente de acordo com o contexto e as suas relações construídas na instituição escolar. A prática pedagógica não se limita apenas ao processo de planejar e executar, mas buscar caminhos para os alunos aprenderem os conteúdos e interagir socialmente sendo uma ferramenta significativa.

Consoante com Lima (2009): “A afirmação da identidade profissional implica na compreensão dela mesma. Porém, temos de ressaltar que, conceituar identidade, envolve uma grande complexidade pelo fato de ser um termo polissêmico, o que permite ser usado de maneira variada nas ciências sociais e áreas afim. (p.5o). Com isso, na formação do docente não consegue definir apenas em uma única vertente o seu significado, pois, a sua definição é um conjunto de fatores e experiências vividas pelo docente de modo a buscar uma adequação com o uso das práticas pedagógicas no intuito de aprimorar o campo educacional.

Percebe-se que muitos docentes não conseguem refletir sobre que fatores podem atrapalhar para que o próprio não consiga perceber a sua identidade profissional, outros ocultam por pensar que é desnecessário. Portanto, a necessidade de debater como formar uma identidade profissional do docente é essencial para conhecer como atuar na educação conforme o contexto histórico atual na sociedade.

\section{REFLEXÕES SOBRE A PROFISSÃO DOCENTE}

Docência é uma profissão de complexidade para todos os formados em licenciatura, pois no Brasil, a preocupação maior que interfere no processo de ensino-aprendizagem dos alunos está interligada desde os conhecimentos adquiridos pelos alunos até a infraestrutura da escola. A docência é uma profissão que a anos é praticada, conforme os contextos históricos, passado por muitas civilizações para uma aquisição ao saber da sociedade.

Os contextos históricos contribuíram para o crescimento da formação docente e com isso a repercussão dos altos e baixos dessa profissão. Por um lado, destaca-se o crescimento de alunos nas escolas, tecnologias como auxiliar para os docentes ministrar as suas aulas, 
equipes de profissionais na escola competentes, etc. Mas por outro lado, possui o abandono pelas autoridades no investimento dos profissionais em educação, falta de incentivo dos alunos em estarem na escola com intuito de aprenderem, desmotivação profissional dos docentes por não ver na sua profissão à devida valorização, etc.

Esses aspectos, de acordo com Lima (2009) são constantemente presente no ambiente escolar e interfere na escolha dessa profissão, pois:

\begin{abstract}
A escolha de uma atividade profissional requer uma tomada de decisão das mais importantes na história de vida de um indivíduo, pois muitos são os fatores que contribuem para tal decisão, dentre estes, destacamos aspectos relacionados à questão da tradição familiar, interesses dos pais, status da profissão, e principalmente, a opção se dá pelo status social que a profissão pode determinar para a pessoa, bem como pela afinidade e o grau de satisfação pessoal e profissional. A compreensão de como nos tornamos um profissional competente é fundamental para a construção da identidade profissional e, dessa forma, para nos comprometermos (ou não) com excelência no exercício da atividade profissional. $(\mathrm{p} \cdot 46)$.
\end{abstract}

A autora destaca principalmente a construção da identidade profissional conforme a própria decisão do indivíduo quando escolhe a profissão da docência. Entretanto, muitos desses docentes atuam apenas pelo simples motivo de estabilidade, por ser um dos empregos mais fáceis de adquiri ou por não ter outra condição de arcar um curso em outra área.

Priorizar a formação do docente é um dos pontos de partida para que construa a reflexão da sua atuação com a sala de aula, pois é característica da educação constantemente sofrer mudanças devido à evolução da sociedade e os seus contextos históricos. Nessa visão, existe uma definição e a função da docência que mostre sua excelência a estabelecer como vínculo social, que:

Ser professor competente implica, pois, produzir um saber fazer pedagógico contextualizado, reflexivo e comprometido com as mudanças e as inovações contextuais. Não basta somente levar em conta o saber, mas é preciso querer saber fazer reflexivamente e, assim, torna-se necessário ter a percepção da percepção, ou seja, a percepção crítica da trajetória profissional, de como se dá o seu envolvimento e os investimentos com a atuação docente, no sentido de ensinar e aprender no quotidiano do trabalho educativo, consciente das suas implicações e do rumo a seguir. O professor compreenderá as dimensões da sua competência na prática pedagógica quando perceber o alcance de seu saber e se estiver predisposto a usar uma visão crítica da realidade, para fazer intervenção crítica na sociedade. Implica, portanto, em tomar partido, sair da neutralidade, assumir compromissos inerentes à ação educativa. (LIMA, 2009, p. 52). 
A autora, em poucas palavras, menciona que a docência na sua formação para estabelecer a qualidade de competente requer a prática dos sentidos, na prática do ato de ensinar na busca de uma relação de contribuição entre os sujeitos envolvidos nesses processos. Não adianta praticar a docência e achar que ser neutro no campo educacional é a solução para um crescimento da aprendizagem, exige uma postura participativa dos docentes.

Tal fato, é um caso de prática didática onde deve ser trabalhada constantemente na formação do docente. Em razão dessa ferramenta ter por princípio: “(...) compreendemos que a didática caracteriza-se como componente formativo que possibilita reflexões críticas sobre o saber ensinar, articulando diferentes dimensões do processo didático.” (LIMA, 2009, p.18).

A didática é multifuncional e desenvolve diversas áreas no contexto educacional, não se caracteriza apenas pelo ato de planejar, mas procurar engajamento e investimento na melhoria da educação onde o docente possa refletir as condutas e avaliar a si mesmo. Já que, "O encontro com a didática proporcionou indagações e conflitos sobre qual seria realmente o objeto de estudo da didática e os seus elementos constitutivos.” (LIMA, 2009, p. I9). Devido à diversidade que a didática pode apresentar na construção da aprendizagem dos alunos, muitos docentes acabam a descartar o fato de "como fazer", dessa forma acomodamse.

$\mathrm{Na}$ licenciatura, não basta apenas o docente ter a formação sem ter o domínio de uma didática diferenciada da tradicional que é o ato de planejar, deve de acordo com Ximenes (2009): "Nesse contexto, ressaltamos a diversidade de problemáticas educacionais presentes na docência do educador do Ensino Superior, tais como: o trabalho docente, os saberes, o desenvolvimento de competências, a identidade profissional.” (p.15). Visto que, isso caracteriza uma didática contemporânea, preocupada com a sua prática de acordo com a sua necessidade, focada de olhar ao redor da escola e preocupar-se com a educação, não apenas com o domínio de conteúdo e reprodução como requisito da formação do docente.

Outro ponto de vista que Lima (2009) destaca é: "Repensar a formação inicial e continuada de professores na contemporaneidade é uma proposta atual e necessária para compreender a identidade do professor no percurso do tornar-se um bom profissional 
docente. (p.48). Assim, o docente exercerá a profissão com mais retorno a seu crescimento e ainda contribui esse desenvolvimento para trocas de experiências entre a categoria, principalmente na formação dos docentes por diversas instituições de ensino.

Logo, a profissão docente define-se diante desses argumentos de modo que:

O exercício da profissão docente exige muito mais, pois a prática de ensinar é multifacetada. O professor precisa saber planejar, executar o planejamento, avaliar o ensino e a aprendizagem entre outras coisas relativas à ação docente. Considerando, pois, às múltiplas exigências da prática pedagógica, compreendemos que a formação profissional deve alicerçar-se em saberes de natureza diversas para que o professor possa responder às atuais exigências da formação integral do educando e, especialmente, assumindo e investindo no ensino de qualidade. (LIMA, 2009, p.47).

Requer, desse modo, que o docente na sua profissão consiga praticar a ação de docência com a prática pedagógica voltada a uma questão de diversidade social que atualmente pode ser encontrada no cenário educacional na preocupação da busca da qualidade de ensino. Portanto, Lima (2009) aborda que o intuito da profissão da docência é “formar indivíduos críticos e conscientes para o exercício da cidadania." Por isso, cabe a profissão da docência estar inserido na sociedade com observação, principalmente no contexto social, isso implica num contexto de ser cidadão ativo diante das situações que a profissão pode apresentar.

Em suma, a profissão docente tem por finalidade: "Desse modo, a profissão docente pressupõe o compromisso político-social, envolvendo a imersão de educadores e alunos, em um processo de construção de conhecimentos, saberes, competências e identidades pessoais e profissionais." (XIMENES, 2006, p.15). Acrescenta-se também que:

\footnotetext{
A prática docente pressupõe, portanto, a atuação do professor norteada por conhecimentos específicos da profissão, fundamentada numa base de conhecimentos teórico-práticos que o professor deve dominar, articular e transformar no contexto do ensino, mantendo-se coerente com a dimensão ética dessa prática. Assim, percebemos que na prática pedagógica, a troca de experiências entre os professores conduz não só a reflexão sobre a prática, mas também, ao questionamento sobre esta e à socialização dos saberes, fazendo com que o professor assuma tanto o papel de formador, quanto o de investigador da prática. (LIMA, 2009, p. 5I).
}

De uma parte, a profissão docente é uma construção contínua do processo didático de um modo social na busca da construção das identidades pessoais e profissionais. Já por 
outra complementa que a profissão docente é o desenvolvimento de conhecimentos tanto teóricos como práticos conforme o processo de ensinar com a socialização dos saberes e com a função de formador e investigador na aprendizagem.

\section{PERPECTIVAS DA IDENTIDADE E PROFISSÃO DOCENTE NA LICENCIATURA}

Licenciar não é apenas como sugere Barbosa (2009) com o seguinte aspecto: "Nesse conceito, o professor é aquele que ensina, isto é, dispõe os conhecimentos aos alunos. Se estes aprenderam ou não, não é problema do professor, especialmente do aluno.” (p.9). Embora muitos educadores pensem no tradicionalismo, a sociedade necessita que o ensino seja cada vez mais dinâmico no ato da aprendizagem, dessa maneira o docente é a chave para a evolução do ensino dos conhecimentos com a sua prática pedagógica na busca de inová-la aos alunos.

Nesse contexto, os professores deveriam possuir uma prática pedagógica “(...) multidimensional; as dimensões humana, técnica e político-social da prática pedagógica devem ser compreendidas e trabalha das de forma articulada. (BARBOSA, p.8). Visto que está se tratando de sujeitos (os alunos) que necessitam ser incentivados a busca do conhecimento, por isso, o docente é a peça fundamental na educação, fundamento este preservado nos cursos de licenciaturas,

O desenvolvimento da identidade do docente mediante a licenciatura é um desafio complexo, para as instituições de ensino existe a barreira em que o docente não sabe-lhe dar com diversas situações sociais, além disso, disfarçam os acontecimentos não porque não sabem, mas a falta de interesse em discuti-las ou agir. Desse modo, cabe aos cursos de licenciatura fazer com que: "Estas questões se entrelaçam com a preocupação em se formar um professor reflexivo, e isto tem sido muito mais forte diante das crises vividas pelos profissionais docentes, crises de identidade, de saber exercer a docência, crise de confiança em seu conhecimento." (LIMA, 2009, p. 38).

A importância de o docente verificar a sua didática é uma das ferramentas fundamentais da busca da identidade, já que a licenciatura dispõe de mecanismos, como a metodologia de ensino: 
Para tanto, temos um grande desafio social, que é de responsabilidade também da educação que, além da qualificação profissional, deve promover a capacidade de afirmação da condição do indivíduo como cidadão considerando necessário que o conhecimento seja um processo de busca de identidade do sujeito, como um dar-se constante, que evidencia o movimento do social, a partir da transformação e afirmação das suas visões de mundo e de si mesmo no contexto social e profissional. (LIMA, 2009, p. 64).

A autora vê no docente a função de formar cidadãos para a busca da sua identidade, na qual estão inseridos na sociedade e profissionalmente. Pois, a partir disso o aluno pode construir e relacionar a identidade social, a identidade pessoal e a identidade profissional na busca do conhecimento.

A autora vê no docente a função de formar cidadãos para a busca da sua identidade, onde estão inseridos na sociedade e profissionalmente. Pois, a partir disso o aluno pode construir e relacionar a identidade social, a identidade pessoal e a identidade profissional na busca do conhecimento.

Barbosa (2009) ainda afirma que “(...) os professores são profissionais essenciais nos processos de mudança das sociedades.” Isso se explica por serem árduos com a realidade em que se encontram na superação de problemas no ambiente escolar e conseguir se dedicar a um ensino de qualidade. E segundo Lima (2009): “Assim sendo, temos que formar profissionais capazes de alcançar a emancipação dos seus saberes e, consequentemente, a afirmação da sua identidade profissional.” Fator dominante para que nos cursos de licenciatura não basta apenas transmitir conteúdos e mandar sem sala de aula nos alunos, praticar uma autonomia educacional.

Para que estes fatos se consolidem perante a formação e atuação de um docente que ingressou ou formou-se na licenciatura, primeiro temos que ater no fato de que: "É pensando a prática pedagógica concreta articulada com a perspectiva de transformação social, que emergirá uma nova configuração para a didática.” (BARBOSA, 2009). Para a autora a didática tem fundamental importância na construção de novos rumos na educação, além disso, destaca que o seu objetivo é voltado para o "como fazer" a prática pedagógica, porém, o seu desenvolvimento só é consolidado "para que fazer” e “porque fazer”. Questões essas que implicam ao docente na licenciatura se preocupar em pesquisar a respeito da comunidade escolar para poder inovar o processo de ensino-aprendizagem na sua disciplina. 
Contudo, didática não é apenas um processo de planejar, nem individualista, pois:

O processo de ensino é uma atividade conjunta de professores e alunos, organizado sob a Direção do professor, com a finalidade de prover as condições e meios pelos quais os alunos assimilam ativamente conhecimentos, habilidades, atitudes e convicções. Este é o objetivo de estudo da didática. Os elementos constitutivos da didática, o seu desenvolvimento histórico, as características do processo de ensino e aprendizagem, e a atividade de estudo como condição do desenvolvimento intelectual. (LIBÂNEO, 1998, p. 29).

Trata-se de um conjunto, uma relação biunívoca, com formas que o aluno adquira o conhecimento dinamizadamente para que a formação do aluno seja repercussão da sua inserção na sociedade.

Diante disso, “(...) a identidade profissional docente se dá na relação com os componentes sociais, institucionais, familiares, com os quais se deve manter uma postura de dignidade e respeito." (LIMA, 2009). Esse desafio é de grande valor para um docente atuar diante de uma sala de aula cheia de alunos, demostrar sua didática, debater com os alunos e incentivar a pesquisa são métodos que podem contribuir para a sua identidade profissional e pessoal.

Um segundo fator que muitos docentes de licenciatura não conseguem construir a identidade é no desafio de educar, devido a diversidade das situações, já que:

Com relação ao desafio de educar se faz necessário desenvolver a capacidade de construir uma identidade complexa, que tenha contida em si o pertencimento em múltiplos contextos e perspectivas: local, nacional e internacional, política, religiosa, artística, econômica, familiar, dentre outras. (DINIZ E RODRIGUES, 2020, p. 14)

Diante dessa observação das autoras, o docente com a formação na licenciatura necessita desde cedo saber praticar a identidade multisetorial para que possa adquirir o conhecimento e sabê-la transmitir diante de uma sala de aula aos alunos. Situações que os alunos tenham vergonha de mencionar para que o docente possa promover um debate social com os alunos e despertar a curiosidade de possuírem conhecimentos em diversos assuntos, desse jeito, não é apenas o professor que está a construir a sua identidade, inclusive os seus alunos.

Assim, esses fatos requerem, observamos que existe a possibilidade do docente a partir do ingresso nos cursos de licenciatura buscar e praticar a sua identidade profissional, e isso, se consolida com a sua construção através desse fator: 
[...] a formação contínua é a mais relevante, pois ela se faz a partir da autonomia docente, de valorização profissional, de escolhas, de envolvimento profissional dentre outros fatores que podem influenciar ou não no "investimento" na profissão, bem como na construção da sua identidade profissional. (BUCHARD et al., 2020, p. 25).

A formação contínua é um dos principais pilares na construção da identidade profissional do docente, pois, nela o docente se redescobre e promove uma reflexão da sua atuação diante do ensinar aos alunos, como interagir com demais professores, quais trabalhos podem ser executados na escola, quais inovações na aprendizagem dos alunos podem ser inseridas e principalmente como contornar os problemas na comunidade escolar para que possa ser um sujeito reflexivo.

\section{CONSIDERAÇÕES FINAIS}

A Docência Superior deve começar desde o início dos cursos de formação, principalmente na licenciatura a abordar com os alunos sobre a identidade profissional e buscar formas de os alunos que serão futuros docentes a trabalharem uma relação biunívoca entre a identidade pessoal e a identidade profissional. Isso, serve de suporte para que o docente tenha uma condição de apresentar soluções em diversas situações que o campo do ensino possa trazer.

Trabalhar com a identidade é um dos atributos de análise histórica e social reflexivamente e perspectiva para que o docente possa através da didática estabelecer uma melhor condição em trabalhar na escola, pois o ensino necessita da interação dos seus membros escolares e da contribuição da formação de cada um.

Não se pode ver apenas uma função didática como planejar, executar e avaliar, mas que ultrapasse as fronteiras na aquisição de conhecimento. Através do ato de adequar a situações que a sala de aula apresenta, ato de inovar o conhecimento de maneira científico aos alunos e o ato de buscar a identidade dos alunos para poderem conquistar o seu espaço na sociedade. 
O docente quando está ou formou-se em um curso de licenciatura deve buscar novos conhecimentos, aprimorar a conduta da relação aluno-professor e vice, e versa e estabelecer integração do conhecimento com a pesquisa aos alunos.

Diante do contexto apresentado, o questionamento feito no início desse artigo, podemos obter a identidade quando existir a troca de discussões em um curso de licenciatura com os futuros docentes questionamentos a ser respondidos como: "O que é ser professor?"; "Que tipo de professor você é ou quer ser?"; "Você como docente está preparado para enfrentar as situações diversas no ambiente escolar?”; “Por que decidiu ser professor?”; Você está pronto para atuar como professor?”.

Depois disso, o docente pode abrir a discussão para incentivar os alunos a uma docência com a busca das suas próprias didáticas, visto que é na teoria-prática que a identidade possa ser desenvolvida com as exposições de diversas situações do ambiente escolar.

O intuito da busca da identidade do docente é socializar, dinamizar e absorver conhecimentos sobre seu campo de trabalho, com o intuito de saber refletir e buscar amenizar os problemas no processo de ensino-aprendizagem, fator este que deve os cursos de licenciatura desenvolver para consolidar efetivos educadores.

\section{REFERÊNCIAS}

BARBOSA, J. R. A. Didática no Ensino Superior. Curitiba: IESDE Brasil S.A., 2009. Disponível em: 〈http://www2.videolivraria.com.br/pdfs/23988.pdf >. Acesso: 06/o4/202I.

BURCHARD, C. P. et al. Construção da identidade profissional docente: caminhos e percalços. In: NEU, A. F.; MARCHESAN, L. J. S. C. (Org.). Construção da identidade profissional docente [recurso eletrônico]: formação, saberes e experiências, Nova Xavantina: Pantanal, 2020, p.I7- 28. Disponível: <https://editorapantanal.com.br/ebooks/2020/construcao-da-identidade-profissionaldocente-formacao-saberes-e-experiencias/ebook.pdf >. Acesso: 06/o4/2021.

DINIZ, M. I. G. A identidade profissional docente e seu papel político pedagógico na sociedade do conhecimento. In: NEU, A. F.; MARCHESAN, L. J. S. C. (Org.). Construção da identidade profissional docente [recurso eletrônico]: formação, saberes e experiências, Nova Xavantina: Pantanal, 2020, p.7-16. Disponível: 
$<$ https://editorapantanal.com.br/ebooks/2020/ construcao-da-identidade-profissionaldocente-formacao-saberes-e-experiencias/ebook.pdf>. Acesso: 06/04/202I.

LIBÂNEO, J. C. Didática. São Paulo: Cortez, 1998.

LIMA, M. G. S. A constituição da identidade profissional: desvelando significados do ser professor de didática. Teresina: Universidade Federal do Piauí - Centro de Ciências da Educação, 2009. Disponível: 〈https://www.livrosgratis.com.br/ler-livro-online-77825/aconstituicao-da-identidade-profissional-docente--desvelando-significados-do-serprofessor-e-didatica $>$. Acesso: 07/04/2021.

NEU, A. F.; MARCHESAN, L. J. S. C. Formação e atuação docente: reflexões sobre os saberes docentes mobilizados no século XXI. In: NEU, A. F.; MARCHESAN, L. J. S. C. (Org.). Construção da identidade profissional docente [recurso eletrônico]: formação, saberes e experiências, Nova Xavantina: Pantanal, 2020, p.29-42. Disponível: <https://editorapantanal. com.br/ebooks/2020/construcao-da-identidade-profissionaldocente-formacao-saberes-e-experiencias/ebook.pdf>. Acesso: 06/04/2021.

UEG. O que é Pesquisa Bibliográfica. Goiânia: Universidade Estadual de Goiás, 2008. Disponível:

em: 〈http://www.ueg.br/noticia/36347_o_que_e_pesquisa_bibliografica\#: :text= A\%20Pesquisa\%20Bibliográfica\%20compreende\%200,-line\%20ou\%20cd-rom>. Io/04/2021.

XIMENES, A. O. A identidade profissional docente no Ensino Superior. Recife: Universidade Federal de Pernambuco - Programa de Pós-Graduação, 2006. Disponível: $\langle$ http://repositorio.ufpe.br/bistream/I23456789/4476/I/arquiv05325_I.pdf〉. Acesso: 08/04/2021. 